\title{
Missed Abortion in a Tertiary Hospital of Eastern Nepal: Efficacy of Sublingual versus Vaginal Misoprostol
}

\author{
Rani Jha, ${ }^{1}$ Manoj Rungta, ${ }^{2}$ Shailesh Kumar $\mathrm{Jha}^{3}$ \\ 'Department of Obstetrics and Gynecology, Janaki Medical College and Teaching Hospital, Janakpur, Nepal ${ }^{2}$ Department \\ of Radiology, Janaki Medical College and Teaching Hospital, Janakpur, Nepal ${ }^{3}$ Department of Emergency Medicine, Janaki \\ Medical College and Teaching Hospital, Janakpur, Nepal
}

\section{ABSTRACT}

\section{Introduction}

Missed abortion is a nonviable intrauterine pregnancy in the presence of a closed cervix and little or no abdominal cramping. WHO recommends Misoprostol as a safe drug in the medical management of missed abortion. This study was conducted to study the efficacy of sublingual versus vaginal misoprostol in the medical management of missed abortion.

\section{Methods}

A hospital based prospective study was carried out among 212 women with confirmed missed abortion who received $800 \mu \mathrm{g}$ misoprostol either sublingually or vaginally for the medical management. All women were admitted to hospital for 2 days for observation. If the pregnancy was not completely evacuated in 2 days following misoprostol administration, manual vacuum aspiration or dilatation and curettage was performed for completion. Efficacy was defined as the percentage of women discharged without the need for manual vacuum aspiration or dilatation and curettage.

\section{Results}

The efficacy of $800 \mu \mathrm{g}$ misoprostol was high and statistically significant in the sublingual group. Success rate was $80.19 \%$ with sublingual route whereas it was only $59.43 \%$ with vaginal route ( $p$-value $=0.001)$. Incidence of complications and side effects like bleeding, abdominal pain, diarrhea and fever was significantly higher in sublingual group.

\section{Conclusions}

In the medical management of missed abortion sublingual misoprostol achieved a higher rate of complete abortion in comparison to the vaginal route. However, sublingual route showed more adverse effects.

Keywords: medical abortion, misoprostol, missed abortion.

Correspondence: Dr. Rani Jha, Department of Obstetrics and Gynecology, Janaki Medical College and Teaching Hospital, Janakpur, Nepal. Email: ranijhaobgyn@gmail.com. Phone: +977-9844025466. 


\section{INTRODUCTION}

Abortion is a pathologic process resulting in unintentional termination of the pregnancy prior to 20 weeks' gestation. ${ }^{1}$ Missed abortion is defined as a nonviable intrauterine pregnancy in the presence of a closed cervix and little or no abdominal cramping. ${ }^{1}$ Its incidence rate is approximately $15 \%$ in all clinically recognized pregnancy. ${ }^{2}$ Surgical dilatation and curettage or manual vacuum aspiration (MVA) is considered as the traditional method of missed abortion management. ${ }^{3}$ Even though MVA and dilatation and curettage are highly effective method of treatment of missed abortion, these procedures also have serious complications associated with anesthesia, uterine infection, uterine perforation with or without injury to adjacent organs or Asherman's syndrome. These complications can cause prolonged morbidity and may affect the future fertility of the woman. Rarely these surgical interventions may prove to be fatal. In modern times availability and efficacy of pharmacological drugs to terminate pregnancy i.e. medical method of abortion has limited the use of surgical procedures. Misoprostol is one such drug that can be used either on its own or in combination with Mifepristone for the abortion management.Misoprostol is a prostaglandin E1 analogue that is easy to handle and store. Noninvasiveness and proven cost-effectiveness of misoprostol offers several advantages in abortion care. It reduces the need for skilled surgical abortion providers, equipment, sterilization and anesthesia, and offers a non-invasive and highly acceptable option to pregnant women. ${ }^{4} \mathrm{WHO}$ recommends oral, buccal, sublingual or vaginal route for the administration of Misoprostol in medical management of abortion. ${ }^{5}$ Several studies have compared the efficacy of various rotes of misoprostol administration without coming to convincing conclusion about one route or the other. ${ }^{6,7}$ This study was conducted with the aim of comparing the efficacy and side effects of one route over the other i.e. sublingual vs. vaginal misoprostol in the treatment of missed abortion.

\section{METHODS}

The present prospective study was conducted in the Obstetrics and Gynecology Department of the Janaki Medical College Teaching Hospital (JMCTH), Janakpur. The study was conducted to compare the efficacy and side effects of sublingual versus vaginal route administration of misoprostol in the management of missed abortion. As per recommendation of National Institute for Health and Care Excellence (NICE) a single dose of $800 \mu \mathrm{g}$ of misoprostol was used by vaginal or sublingual route for management of missed abortion. ${ }^{8}$ The study group included 212 women with diagnosis of first trimester silent abortion $<13$ weeks gestation, over a period of June 2019 to June 2021. Women were included in the study after taking informed consent. Ethical approval was taken from Ethical Review Committee of JMCTH. The data was collected in the form questionnaire from all the candidates. Statistical analysis was performed using Microsoft excel version 16.16.27 and SPSS version 18.0 .

\section{Criteria}

Inclusion Criteria: Women with an ultrasound diagnosis of missed abortion $<13$ weeks gestation

Exclusion Criteria: Patients refused the medical treatment, incomplete abortion, inevitable abortion, suspicion of an extra uterine pregnancy, molar pregnancy, missed abortion associated with any signs of sepsis, abnormal blood count tests obtained routinely, patients have contraindications of Misoprostol, previous cesarean section or scarred uterus, any systemic disease

All eligible women were assigned a number. 
Women with odd numbers were assigned for sublingual administration of $800 \mu \mathrm{g}$ misoprostol tablets and those with even numbers were administered $800 \quad \mu \mathrm{g}$ misoprostol tablets vaginally. As per WHO guidelines sublingual pills were placed under the tongue and swallowed after 30 minutes; vaginal pills were placed in the vaginal fornices (deepest portions of the vagina) and the individual was instructed to lie down for 30 minutes. ${ }^{5}$

The primary outcome of the study was measured as the efficacy of the treatment in inducing complete abortion without the need of any surgical intervention (MVA or dilatation and curettage). Successful medical management of abortion was defined as no need for surgical intervention.

Side effects of misoprostol administration were recorded as other outcomes of the study.

After 2 days of misoprostol administration ultrasound was performed to confirm complete abortion. All women with complete abortion were discharged from the hospital with an appointment for follow-up. Manual vacuum aspiration or dilatation and curettage was performed for women with incomplete abortion. All Rh-ve women were given intramuscular 300 $\mu \mathrm{g}$ Anti-D injection. Clinical outcome of the medical management, any surgical intervention needed and side-effects were noted.

\section{RESULTS}

All 212 women were admitted in the hospital and followed-up for 2 days. One hundred and six participants were included in each group i.e. sublingual and vaginal administration group. The age range among the participants was from 16 to 35 years. There was not much difference in the mean gestational age in the sublingual and vaginal misoprostol groups: 8.93 and 8.92 weeks respectively. (Table 1.)

\begin{tabular}{|l|l|l|l|}
\hline \multicolumn{3}{|l|}{ Table 1. Demographic character of participants } \\
\hline & $\begin{array}{c}\text { Sublingual } \\
\text { Group }\end{array}$ & $\begin{array}{c}\text { Vaginal } \\
\text { Group }\end{array}$ & \\
\hline & Mean & Mean & P-value \\
\hline Age & 22.83 & 23.08 & 0.345 \\
\hline Gestational age & 8.93 & 8.92 & 0.473 \\
\hline Gravida & 2.41 & 2.33 & 0.318 \\
\hline Para & 1.21 & 1.12 & 0.280 \\
\hline Previous abortion & 0.45 & 0.47 & 0.434 \\
\hline
\end{tabular}

Table 2. Distribution of participants according to age

\begin{tabular}{|l|l|l|}
\hline Age (years) & Sublingual Group & Vaginal Group \\
\hline$<19$ & $23(21.69 \%)$ & $28(26.41 \%)$ \\
\hline$>20-24$ & $45(42.45 \%)$ & $38(35.84 \%)$ \\
\hline$>25-29$ & $18(16.98 \%)$ & $17(16.03 \%)$ \\
\hline$>30-34$ & $18(16.98 \%)$ & $22(20.75 \%)$ \\
\hline$>35$ & $2(1.88 \%)$ & $1(0.94 \%)$ \\
\hline
\end{tabular}

There was not much difference between the women of two groups in terms of number of pregnancy. Majority of the women were pregnant for the second time.

Table 3. Obstetric characteristic of participants

\begin{tabular}{|l|c|c|}
\hline \multicolumn{1}{|c|}{$\begin{array}{c}\text { Number of } \\
\text { pregnancy }\end{array}$} & $\begin{array}{c}\text { Sublingual } \\
\text { Group }\end{array}$ & $\begin{array}{c}\text { Vaginal } \\
\text { Group }\end{array}$ \\
\hline Primi & $26(24.52 \%)$ & $25(23.58 \%)$ \\
\hline Second pregnancy & $39(36.79 \%)$ & $42(39.62 \%)$ \\
\hline Third pregnancy & $18(16.98 \%)$ & $23(21.69 \%)$ \\
\hline$\geq$ Fourth pregnancy & $23(21.69 \%)$ & $16(15.09 \%)$ \\
\hline
\end{tabular}

Table 4. Effectiveness of sublingual versus vaginal misoprostol for the management of missed abortion

\begin{tabular}{|l|c|c|c|c|}
\hline & $\begin{array}{c}\text { Sublingual } \\
\text { Group }\end{array}$ & $\begin{array}{c}\text { Vaginal } \\
\text { Group }\end{array}$ & RR & P-value \\
\hline $\begin{array}{l}\text { Complete } \\
\text { evacuation }\end{array}$ & $\begin{array}{c}85 \\
(80.19 \%)\end{array}$ & $\begin{array}{c}63 \\
(59.43 \%)\end{array}$ & 0.49 & $0.001^{*}$ \\
\hline $\begin{array}{l}\text { Incomplete } \\
\text { evacuation }\end{array}$ & $\begin{array}{c}21 \\
(19.81 \%)\end{array}$ & $\begin{array}{c}43 \\
(40.57 \%)\end{array}$ & 2.05 & $0.001^{*}$ \\
\hline Total & $106(100 \%)$ & $\begin{array}{c}106 \\
(100 \%)\end{array}$ & & \\
\hline
\end{tabular}

*The result is significant at $p<.05$

Sublingual administration of $800 \mu \mathrm{g}$ misoprostol tablet was found to be more effective in inducing 
complete abortion in comparison to the vaginal route administration. Success rate was $80.19 \%$ with sublingual route whereas it was only $59.43 \%$ with vaginal route $(\mathrm{p}$-value $=0.001)$.

Even though sublingual administration of misoprostol was more effective in achieving the objective, this route also had more side effects in comparison to the vaginal route. (Table 5.)

*The result is significant at $p<.05$

**The result is not significant at $p<.05$

$* * *$ oral temperature $>37.80 \mathrm{C}$ sublingual route of misoprostol associated with shorter time interval for complete abortion and highly acceptable to clients in comparison to vaginal route..$^{12,13}$

Women who underwent MVA or surgical evacuation in our study ( in both groups) had no additional complications, such as excessive blood loss, uterine injury and cervical laceration. It is postulated that surgical evacuation is easier after misoprostol administration as it facilitates

Table 5. Side-effects in sublingual and vaginal misoprostol groups

\begin{tabular}{|l|l|l|l|l|}
\hline & Sublingual Group & Vaginal Group & RR & P-value \\
\hline $\begin{array}{l}\text { Patient with vaginal } \\
\text { bleeding }\end{array}$ & $103(97.16 \%)$ & $71(66.98 \%)$ & 1.45 & $<.00001^{*}$ \\
\hline Bleeding > menstruation & $87(84.46 \%)$ & $20(28.17 \%)$ & 3.0 & $<.00001^{*}$ \\
\hline Bleeding S menstruation & $16(15.54 \%)$ & $51(71.83 \%)$ & & $<.00001^{*}$ \\
\hline Cramp pain & $76(71.7 \%)$ & $69(65.09 \%)$ & 1.1 & $.303^{* *}$ \\
\hline Severe pain & $25(23.58 \%)$ & $12(11.32 \%)$ & 2.08 & $.0187^{*}$ \\
\hline Vomiting & $24(22.64 \%)$ & $11(10.37 \%)$ & 2.18 & $.0164^{*}$ \\
\hline Diarrhea & $62(58.49 \%)$ & $29(27.36 \%)$ & 2.14 & $<0.0001^{*}$ \\
\hline Fever*** & $34(32.07 \%)$ & $21(19.81 \%)$ & 1.62 & $.0413^{*}$ \\
\hline
\end{tabular}

\section{DISCUSSION}

In our study significantly higher success rate was achieved by sublingual administration of misoprostol in the medical management of missed abortion. Sublingual route has added advantage of ease to use and avoidance of discomfort felt by many women in vaginal use.

It was noted in the present study that in spite of a higher success rate sublingual route was associated with more side effects. GemzellDanielsson et al. in their study also found a higher incidence of side-effects with sublingual misoprostol. ${ }^{9}$ Saxena et al. Gomez et al. report higher incidence of side-effects in their study. However, the side-effects did not affect the acceptability of sublingual route. ${ }^{10,11}$ Tanha et al. and Rabiei et al. in their studies regarding medical management of missed abortion, found cervical ripening. Serious surgical complications in abortion management usually arise due to instrumentation of the uterus. ${ }^{14,15}$

\section{CONCLUSION}

Medical abortion care is an important component of comprehensive abortion care. It provides safe, effective and acceptable abortion care in both high- and low-resource settings. The use of medical methods of abortion have contributed to task shifting and sharing and more efficient use of resources. Sublingual use of misoprostol in medical management of abortion need to be used effectively in the worldwide setting. Medical management of missed abortion by sublingual misoprostol was found to be safe, easy to administer, highly effective and acceptable in this study. 


\section{REFERENCES}

1. Jonathan SB. Berek and Novak's Gynecology. Fifteenth Edition. New Delhi( India): Wolters Kluwer India Pvt Ltd;2016

2. Practice Committee of the American Society for Reproductive Medicine. Evaluation and treatment of recurrent pregnancy loss: a committee opinion. Fertil Steril 2012;98:1103-11.

3. Chung T, Leung P, Chung LP, Haines C, Chang AMZ. Medical approach to management of spontaneous abortion using misoprostol. Acta Obstet Gynecol Scand 1997; 76: 248- 251.

4. Blum J, Winikoff B, Gemzell-Danielsson K, Ho PC, Schiavon R, Weeks A. Treatment of incomplete abortion and miscarriage with misoprostol. Int J Gynaecol Obstet. 2007;99(Suppl 2):S1869.

5. https://apps.who.int/iris/bitstream/hand le/10665/278968/9789241550406-eng.pdf

6. ang OS, Lau WN, Chan CC, Ho PC. A prospective randomisedcomparison of sublingual and vaginal misoprostol in secondtrimester termination of pregnancy. BJOG. 2004;111(9):1001-5.

7. Dickinson JE, Evans SF. A comparison of oral misoprostolwith vaginal misoprostol administration in secondtrimesterpregnancy termination for fetal abnormality. Obstet Gynecol.2003;101(6):1294-9.

8. National Institute for Health and Care Excellence guidelines. Ectopic pregnancy and miscarriage: diagnosis and initial management. www.nice.org. uk/guidance/cg154 (2012).

9. Gemzell-Danielsson K, Ho PC, Gómez Ponce de León R, Weeks A, Winikoff B. Misoprostol to treat missed abortion in the first trimester. Int J Obstet Gynecol 2007; 99: 182- 185.

10. Saxena P, Salhan S, Sarda N. Comparison between the sublingual and oral route of misoprostol for pre-abortion cervical priming in first trimester abortions. Hum Reprod 2004; 19: 1- 4 .

11. Gómez Ponce de León R, Wing D, Fiala C. Misoprostol for intrauterine fetal death. Int J Obstet Gynecol 2007; 99: 190193.

12. Tanha, F.D., Feizi, M. and Shariat, M. (2010), Sublingual versus vaginal misoprostol for the management of missed abortion. Journal of Obstetrics and Gynaecology Research, 36: 525-532.

13. RabieiS,KhansariS,FallahM,AjandM. Comparisonofsublingualversusva ginalmisoprostolin theman agementof missedabortions. Biomed. Res. Ther.;6(10):3391-3395.

14. Goldberg AB, Greenberg MB, Darney PD. Misoprostol and pregnancy. N Engl J Medical 2001; 344: 38- 47.

15. Grimes A, Smith S, Withan A. Mifepristone and misoprostol versus dilation and evacuation for midtrimester abortion: A pilot randomised controlled trial. Br J Obstet Gynaecol 2004; 111: 148153.

Citation: Jha R, Rungta M, Jha S. Missed Abortion in a Tertiary Hospital of Eastern Nepal: Efficacy of Sublingual versus Vaginal Misoprostol. JCMS Nepal. 2021 ; 17(4); 347-51. 